\title{
DIREITO PROCESSUAL CIVIL CANADENSE
}

\author{
CANADIAN CIVIL PROCEDURAL LAW
}

José Rogério Cruz e Tucci*

\begin{abstract}
Resumo:
O Autor aborda o Direito Processual canadense, no intuito de demonstrar que, embora recebimento de forte influência de dois sistemas jurídicos - francês e inglês - o Direito canadense ainda apresenta próprias peculiaridades.

Palavras-chave: Direito Processual canadense. Fontes atuais do Processo Civil. Organização judiciária.
\end{abstract}

\begin{abstract}
:
The author discusses the Canadian Procedural Law, in order to demonstrate that, while receiving strong influence of two legal systems - English and French Canadian law still has its own peculiarities.

Keywords: Canadian Litigation. Current sources of Civil Procedure. Judicial organization.

"La responsabilité première du pouvoir judiciaire, une composante de l'État, est d'interpréter et d'appliquer la loi au bénéfice des partie s et dans l'intérêt general de la société. Ce faisant, les tribunaux rendent un service public, participent à la mission de l'État et contribuent au maintien de la paix sociale". ${ }^{1}$
\end{abstract}

1. Nota introdutória

Em decorrência de razões históricas, atinentes à época de sua colonização, o Canadá, que adota o regime federalista, é dividido em 10 províncias (Alberta, British Columbia, Manitoba, New Brunswick, Newfoundland e Labrador, Nova Scotia, Ontario, Prince Edward Island, Quebec e Saskatchewan) e 3 territórios (Northwest Territories, Nunavut e Yukon).

Tendo recebido forte influência de dois sistemas jurídicos, dada a simultânea hegemonia política de franceses e ingleses, o Direito canadense apresenta peculiaridades próprias.

Professor Titular da Faculdade de Direito da USP e Advogado em São Paulo

1 Une nouvelle culture judiciaire, Rapport Comité de révision de la procédure civile, p. 36. 
A vasta Província de Ontário rejeitou formalmente as leis francesas, pelo Constitutional Act de 1791. Mesmo depois da união política das províncias do norte e do sul (Upper and Lower Canada), ocorrida em 1849, o common law continuou eficaz nos territórios do norte do Canadá e, ainda, na região da Columbia Britânica.

Assim, no plano do Direito, as regras de processo civil que vigoram na grande maioria das províncias e territórios foram inspiradas na experiência jurídica do common law, especialmente do direito inglês e estadunidense, adaptadas às exigências e tradições locais. Importa esclarecer que as regras processuais da Província de Ontário (Ontario Rules of Civil Procedure) são, em princípio, aplicadas em quase todos os tribunais canadenses. A Província de Nova Escócia, por outro lado, adota regras próprias, cuja última reforma passou a vigorar em $1^{\circ}$ de janeiro de 2009.

Apenas a Província de Quebec possui um sistema legal marcado pela hibridez: no âmbito civil, o Direito é codificado; enquanto, na esfera penal, imperam as regras do common law.

De observar-se que esta peculiar circunstância, qual seja, a dualidade de sistemas jurídicos vigentes num mesmo país, exige dos operadores do Direito amplos conhecimento e preparo, para exercer a prática forense, respectivamente, no âmbito das regras consuetudinárias e dos textos legais codificados. Apenas à guisa de exemplo, surgem situações inusitadas, como aquela, relativa à competência, em que a demanda é aforada sob as regras do common law, tendo o réu alterado o seu domicílio para a Província de Quebec, regida por outra legislação, que impõe diferentes requisitos para o ajuizamento da ação. ${ }^{2}$

\section{Fontes atuais do processo civil}

O Direito Processual Civil da Província de Ontário é regido pelas já aludidas Ontario Rules of Civil Procedure, que foram recentemente consolidadas pelo Courts of Justice Act 186/10, aprovado em 20 de maio de 2010, para entrar em vigor em $1^{\mathrm{o}}$ de julho seguinte. ${ }^{3}$

A Província de Quebec, a seu turno, depois de mais de 30 anos sob a égide do Code de Procédure Civile, de 1965, houve por bem, em meados da década de 90, promover a revisão da legislação processual civil.

Com efeito, em 1998, Serge Ménard, então Ministro da Justiça, nomeou uma comissão de especialistas (Comité de révision de la procédure civile), presidida por Denis Ferland, Professor de Direito da Universidade Laval (Quebec), com o intuito de atualizar o velho diploma. Depois de 3 anos de estudos e debates, a comissão acabou

\footnotetext{
2 V., a respeito, Edward Veitch, Canada, International Civil Procedure, v. 1, p. 55.

3 Este Act atualizou o precedente Reg. 194/1990.
} 
produzindo um interessante e denso relatório, intitulado Une nouvelle culture judiciaire (também conhecido por Ferland Report), que constituiu o precípuo subsídio para a construção do novo Code de Procédure Civile, promulgado em 2002, com 1.052 artigos e vigente desde $1^{\circ}$ de janeiro de $2003 .{ }^{4}$

Aduza-se que, nos dois sistemas, existem diferentes Rules of Practice, que complementam o arcabouço de normas processuais e se prestam a disciplinar a praxe perante as cortes de justiça.

São estas, portanto, norteadas pelo Constitucional Act de 1982 (que incluiu na Constituição o texto da Canadian Charter of Rights and Freedoms), as fontes primordiais de regência do processo civil canadense.

\section{Organização judiciária}

Os juízes, via de regra, são nomeados pelo governo federal, pelas províncias e pelos territórios, dependendo da jurisdição do respectivo tribunal. As cortes superiores exigem que os candidatos à nomeação tenham pelo menos 10 anos de efetivo exercício na advocacia. O Instituto Judiciário Nacional fomenta o constante aperfeiçoamento dos membros do Poder Judiciário. Ademais, o Conselho Judiciário Canadense exerce o controle sobre a atividade dos órgãos judiciais.

A Suprema Corte do Canadá, situada em sua capital, Ottawa, é o tribunal que, desde 1949, encontra-se no ápice da hierarquia judiciária. É presidido pelo Chief Justice e é composto por mais 8 integrantes (puisne judges), indicados pelo chefe do executivo e recrutados entre magistrados das cortes provinciais superiores ou advogados, com mais de 10 anos de experiência profissional. O Supreme Court Act, de 1970, determina que, pelo menos, 3 juízes provenham da Província do Quebec e 3 juízes da Província de Ontário.

Cumpre anotar que a Suprema Corte reúne-se apenas nos meses de janeiro, abril e outubro, tendo competência recursal para julgar as causas que, por ela, são reputadas relevantes, ou seja, revestidas de public importance; e, ainda, para exercer o controle de constitucionalidade, inclusive para interpretar a Constituição. Edward Veitch esclarece que a Suprema Corte não chega a julgar 100 casos durante o período anual em que se reúne. ${ }^{5}$

\footnotetext{
$4 \quad$ V., sobre a evolução da reforma do CPC, Pierre E. Audet, La réforme de la procédure civile de 2002: un jalon de plus vers l'idéal d'un accès à la justice pour tous?, http://www. cfcj-fcjc.org/docs/2006/audet-fr; 2002 Civil Procedure Reform: Another milestone towards attaining the ideal of access to justice for all?, http://www.cfcj-fcjc.org/docs/2006/audet-en.

5 Canada, International Civil Procedure, v. 1, p. 55.
} 
Cada província ou território possui uma Corte de Apelação Federal, que tem competência recursal para julgar questões referentes à legislação federal (federal statutes).

Os tribunais superiores provinciais (Superior Court of Justice) julgam, em grau de apelação, todas as outras causas atinentes à legislação provincial ou territorial. Anote-se que a mais congestionada, por abranger área territorial com significativa população, é a da Província de Ontário.

Em primeiro grau, também é mantida a mesma divisão funcional entre tribunais federais e provinciais/territoriais.

Há ainda um tribunal especializado em impostos (Tax Court of Canada).

\section{Stare decisis}

Ressalte-se que os dois sistemas jurídicos que vigoram no Canadá - casuístico e codificado - interagem e exercem recíproca influência: quando, por exemplo, o tribunal decide com base na lei escrita, na Província de Quebec, a sentença é considerada precedente vinculante vertical para as demais cortes inferiores, e viceversa.

Ademais, dada a marcante influência do commom law, recebida diretamente da matriz britânica, todos os tribunais canadenses sujeitam-se às decisões da Suprema Corte. A eficácia vinculante do precedente é ínsita ao sistema judicial canadense.

Até 1949, o Judicial Committee of the Privy Council, situado em Londres, ainda detinha competência para rever, em determinadas hipóteses, as decisões da Suprema Corte do Canadá. Depois de tal data, no entanto, com a integral abolição de qualquer ingerência política do Reino Unido, os precedentes daquele órgão judicial inglês exercem apenas influência persuasiva nas cortes canadenses.

É importante salientar que, desde o século passado, os tribunais do Canadá também manifestam grande interesse pela jurisprudência dos Estados Unidos. Afirma-se que a atividade jurisdicional do país vizinho constitui "fonte de informação e de ensino e que representa a experiência de uma nação de fortes tradições democráticas e ideário de liberdade com enfoque dinâmico e evoluído". ${ }^{6}$

Os precedentes judiciais americanos que mais são invocados, com eficácia meramente persuasiva nas cortes canadenses concernem a direitos sociais e garantias individuais. $^{7}$

\footnotetext{
6 Osborne v. Canada (Treasury Board) [1991].

7 Sara Volterra, La giurisprudenza statunitense nelle pronunce della Corte Suprema Federale del Canada, Scintillae iuris - Studi in memoria di Gino Gorla, t. 1, p. 492.
} 
Desde o Colonial Laws Validity Act, de 1865, as regras do common law não incidem quando forem contrárias às leis e aos costumes do povo canadense.

\section{Panorama do processo civil do common law}

Importa salientar que o processo canadense, de um modo geral, é revestido das garantias ínsitas ao due process of law. Na verdade, como explica Patrice Garant, este fundamental princípio, incluído no Canadian Bill of Rights, foi emprestado da $14^{\mathrm{a}}$ Emenda da Constituição Americana, embora a sua interpretação, nos tribunais do Canadá, se afeiçoe mais com a tradição britânica da rule of law, que traduz uma constelação de garantias reconhecidas pela Constituição, tendo, como núcleo central, o direito subjetivo de todos os cidadãos, sem qualquer distinção. ${ }^{8}$

As fases do processo civil que vigora na grande maioria das províncias, disciplinado, como já ressaltado, pelas regras do common law, não diferem, em linhas gerais, daquelas típicas, que predominam nos países de estrutura legal anglo-americana.

O procedimento "comum" encontra-se preceituado pelas Regras 1 a 63 das Ontario Rules of Civil Procedure. O sistema processual que aí impera é também de natureza adversarial, o que implica inarredável prévio acesso aos litigantes de todas as informações necessárias à preparação do caso.

Verifica-se, de logo, a influência da tecnologia da informação no desenrolar do procedimento: a comunicação por telefone, por meio eletrônico e, ainda, a produção de atos processuais mediante videoconferência são amplamente admitidas (R. 1.08 e 4.04).

A demanda então se inicia com a apresentação da petition (ou writ of summons ou statement of claim) pelo autor (plaintiff). As Regras 5.02 e 5.03 traçam a distinção, respectivamente, do litisconsórcio voluntário e do litisconsórcio necessário (joinder of necessary parties) (ativo e/ou passivo). Se o número de litisconsorciados comprometer a celeridade, o juiz poderá determinar a cisão em várias demandas (R. $5.05)$.

A citação (notice of action) é normalmente realizada por auxiliar do juízo (bailiff), com a advertência da incidência dos efeitos da revelia (judgement by default).

$8 \quad$ Patrice Garant, Fundamental Rights and Fundamental Justice, The Canadian Charter of Rights and Freedoms, 2. ed., ed. por Gérald-A. Beaudoin e Ed Ratushny, p. 365-366. 
$\mathrm{O}$ oferecimento da resposta pelo réu (defendant $)^{9}$ pode se limitar à contestação (statement of defense ou reply), informada pela regra da eventualidade; ${ }^{10}$ ou, então, ser ampliada por meio de reconvenção (counterclaim)(R. 27).

O réu pode ainda, v. g., em casos de solidariedade, "chamar ao processo" um co-demandado (crossclaim)(R. 28), ou provocar a intervenção de um terceiro (third party claim)(R. 29).

Os horizontes do objeto do processo, em princípio, se estabilizam com a apresentação da réplica (R. 25.05). Todavia, para assegurar a economia processual, os tribunais, de um modo geral, permitem posteriores emendas nos respectivos arrazoados. Há, sobre essa questão, um famoso precedente: Cp Cardinal v. Canada [1992]. ${ }^{11}$

Denominam-se pleadings as manifestações das partes na fase postulatória do processo, que se prestam, sobretudo, a definir os pontos realmente relevantes que deverão ser objeto de julgamento.

A Regra 20 prevê modalidade de julgamento antecipado (summary judgement), quando a prova documental for suficiente para comprovar a procedência ou a improcedência, ainda que parcial, do pedido deduzido.

Não ocorrendo esta hipótese, inaugura-se, em seguida, a fase instrutória (discovery), que, além de complexa, é reputada crucial. ${ }^{12}$ As provas documental e oral são as comumente produzidas. Se o documento estiver redigido em francês, deve ser vertido para o inglês (R. 4.02.1).

A tutela de urgência encontra expressa previsão nas Regras 40 a 45. Interlocutory Injunction ou Mandatory Order consubstancia-se num provimento judicial de natureza antecipatória, norteado pelo princípio da proporcionalidade ("balance of convenience"), visando a evitar dano irreparável a um dos litigantes. O famoso caso, muitas vezes invocado sobre esse tema, é o precedente Metropolitan Stores Ltd. v. Manitoba Food and Commercial Workers [1987]. ${ }^{13}$

Estão ainda contempladas nas citadas regras medidas de natureza cautelar de recuperação provisória e de conservação da propriedade.

\footnotetext{
9 O prazo para resposta, consoante dispõe a Regra 18, é de 20 dias, se o réu estiver domiciliado na Província de Ontário; 40 dias, se em outro local do Canadá ou dos EUA; e, de 60 dias, se o réu estiver domiciliado em qualquer outro lugar.

10 V., a propósito, Edward Veitch, Canada, International Civil Procedure, cit., p. 59.

11 Cf. Edward Veitch, Canada, International Civil Procedure, cit., p. 59.

12 Garry Watson, Stephen Borins e Neil Williams, Canadian Civil Procedure, ch. 9, p. 1.

13 Janet Walker e Garry Watson, Preliminary or Summary Proceedings: Scope and Importance - General Report (Common Law), XII Congreso Mundial de Derecho Procesal, v. 1, coord. por Marcel Storme e Cipriano Gómez Lara, Universidad Nacional Autónoma de México, p. 221-222, que se reportam ao ensaio de P. Perell, The Interlocutory Injunction and Irreparable Harm, Canadian Bar Review, v. 68, 1989.
} 
Aduza-se que todas estas interlocutory orders são recorríveis por meio de appeal, no prazo de 7 dias, após a autorização do juiz que proferiu a decisão (R. 62.01 e 62.02).

A Regra 50 disciplina espécie de audiência, denominada pre-trial conference, cuja realização pode ser requerida pelas partes, no interregno de 180 dias após a conclusão dos autos para julgamento, visando, em última análise, a efetivação de transação.

O processo se encerra, em primeiro grau, pelo julgamento monocrático (trial), que desafia o recurso de apelação.

A interposição desta condiciona-se à expressa autorização do tribunal ( $\mathrm{R}$. 61.03). O prazo do recurso é de 30 dias, a contar da ciência da referida permissão (R. 61.04). Se o juiz do tribunal, a quem dirigido o recurso, entender, de logo, que a apelação é "frívola e vexatória", poderá subordinar a sua admissão ao pagamento de custas (R. 61.06). O apelado tem a faculdade de apresentar, no prazo de 15 dias, crossappeal (ou seja, recurso adesivo)(R. 61.07).

A Regra 64 e seguintes estabelecem alguns procedimentos especiais (particular proceedings), dentre eles:

a) o do "processo simplificado" (simplified procedure), para as ações individuais de valor igual ou inferior a $\$$ 100.000 (R. 76), que tramita de modo menos formal e que, por isso, se encerra, em regra, num lapso temporal mais abreviado $^{14}$; e

b) o do "case management", nas situações que reclamam mais acentuada ingerência do tribunal, em decorrência de práticas provenientes da tradição, dos costumes ou do direito aplicável no foro da demanda (R. 77.01.2). De acordo com as Regras 77.04 e 77.08, o juiz ou o case management master dispõe de amplos poderes para programar a tramitação do processo com diferentes prazos e fases.

A execução da decisão condenatória se inicia mediante a expedição, nos próprios autos, de uma ordem de pagamento, de entrega ou restituição da coisa, ou de obrigação de não fazer (R. 60).

O descumprimento da determinação judicial abre ensejo a que o juiz tome providências contra o devedor, por meio de diversas medidas coercitivas, dependendo

14 V., enaltecendo a recente reforma processual, em particular, a adoção do processo simplificado, que tornou bem menos onerosa a fase da discovery, Charles B. Wagner, Rules of Civil Procedure in Ontario Changes as a January, 1, 2010, http://www.hg.org/article.asp?id=7869. 
da situação concreta, quais sejam: writ of seizure and sale, writ of sequestration, writ of possession, contempt order (R. 60.07, 60.09, 60.10 e 60.11).

6. Panorama do processo civil do civil law

A estrutura formal do precedente CPC de 1965 foi mantida no atual diploma. Nota-se, sem qualquer dificuldade, que a legislação codificada da Província do Quebec não se diferencia daquelas clássicas, que dominam o processo civil nos países que receberam influência do Direito europeu-continental.

A $1^{\text {a }}$ parte do art. $2^{\circ}$ do Code de Procédure Civile contém importante regra atinente à instrumentalidade do processo, determinando aos juízes que, salvo em casos de nulidade insanável, devem envidar todo esforço para aproveitar o processo e julgar o mérito da controvérsia.

O princípio da duração razoável do processo está prescrito na $2^{\mathrm{a}}$ parte do art. $2^{\text {o: }}$ "Ces dispositions doivent s'interpréter les unes par les autres et, autant que possible, de manière a faciliter la marche normale des procès, plutôt qu'à retarder ou à y mettre fin prématurément". ${ }^{15}$

$\mathrm{O}$ art. $5^{\circ}$ consagra expressamente o princípio do contraditório, ao determinar que: "Il ne peut être pronuncé sur une demande en justice sans que la partie contre laquelle elle est formée n'ait été entendue ou dûment appelée". ${ }^{16}$

O Processo Civil é ainda informado por outros importantes princípios, como, v. g., o da publicidade (art. 13) e o do dever de fundamentação dos atos decisórios (art. 463).

O CPC de 2002 encontra-se seccionado em 10 livros, que englobam os procedimentos de jurisdição voluntária (1. VI), a arbitragem (1. VII) e as ações coletivas (1. IX).

O procedimento comum se divide em dois procedimentos contenciosos bem delineados: a) o procedimento ordinário de primeiro grau (art. 110 e ss.), e b) o procedimento para pequenas causas (art. 953 e ss.).

Como novidades que merecem ser destacadas, observa-se que o grave problema da demora do processo, levou o legislador a instituir, no art. 151 do Code de Procédure Civile, a tentativa compulsória de conciliação. Sob a rubrica case management, verifica-se que, antes de o réu oferecer resposta, as partes “devem negociar

15 Em vernáculo: "Estas disposições devem ser interpretadas sistematicamente, tanto quanto possível, de modo a facilitar a marcha normal do processo, ao invés de retardá-la ou atribuir-lhe um fim prematuro" (trad. livre).

16 Em vernáculo: "Nenhuma demanda poderá ser julgada, a menos que a parte contra a qual foi ela ajuizada tenha sido ouvida ou regularmente cientificada" (trad. livre). 
um acordo", no prazo peremptório de 180 dias, ou de 1 ano, se a causa for de direito de família (art. 151.1).

A negociação se desenrolará perante um juiz designado para acompanhar o diálogo travado entre as partes. Tal ato processual se desenvolve sem quaisquer formalidades (art. 151.14 e ss.).

Resultando frustrada a tentativa de acordo, inaugura-se então a "fase contenciosa", cabendo ao juiz estabelecer um detalhado cronograma, dependendo da natureza e complexidade da causa, a ser seguido pelos litigantes (art. 151.6).

A resposta do réu compreende a apresentação de exceções declinatórias (arts. 163 e 164), dilatórias (art. 168) e peremptórias (arts. 165 e ss.); e de contestação (art. 172 e ss.).

A emenda da petição inicial e da defesa é possível, a qualquer momento, antes do julgamento (art. 199 e ss.).

O CPC admite a intervenção voluntária de terceiros (art. 208 e ss.).

Aduza-se que a reforma processual também se inspirou nos princípios da economia e da proporcionalidade, ao impor a todos os envolvidos (juízes, auxiliares da justiça e advogados) um verdadeiro comprometimento com a celeridade. Devem eles, pois, envidar todo esforço pessoal para que a tramitação de determinado processo seja proporcional, em termos de despesas e tempo exigidos, à natureza e complexidade da demanda. ${ }^{17}$

Ademais, o procedimento a ser observado no processamento das pequenas causas (small claims) veio aperfeiçoado no livro VIII do CPC, admitindo inclusive o pedido contraposto do réu. O art. 953 dispõe que este procedimento incide nos litígios que não excedam o valor originário de $\$ 7.000$, não havendo necessidade de as partes se fazerem representar por advogado (art. 959). Não obstante, se a causa for reputada complexa, o juiz poderá determinar que os litigantes contratem um advogado, cujos honorários, de acordo com o Legal Aid Act (ch. A-14), serão suportados pelo governo.

A produção da prova segue o sistema da discovery, incumbindo às partes a troca prévia dos elementos de convicção de que se valerão perante o tribunal (art. 397 e ss.).

Muito se discutiu, durante os trabalhos de reforma do CPC, a possibilidade de o tribunal determinar ao réu, na ação de investigação de paternidade, a submissão ao exame pericial pelo método de DNA, em possível afronta ao princípio fundamental de respeito à integridade física do cidadão, consagrado no art. $7^{\circ}$ da Charte Canadiense des Droits et Libertés. Não obstante, prevaleceu o entendimento de que, por imperativo

17 Pierre E. Audet, La réforme de la procédure civile de 2002: un jalon de plus vers l'idéal d'un accès à la justice pour tous?, http://www. cfcj-fcjc.org/docs/2006/audet-fr; 2002 Civil Procedure Reform: Another milestone towards attaining the ideal of access to justice for all?, http://www.cfcj-fcjc.org/docs/2006/audet-en. 
de ordem pública e em determinados casos, não há qualquer ofensa à pessoa ao ser-lhe imposta a ordem de se submeter à referida perícia (art. 414).

Encerrada a instrução, segue-se o julgamento da demanda (art. 462 e ss.). Ao juiz é defeso acolher o reconhecimento do pedido nas causas de estado da pessoa (art. 457).

A parte que foi condenada por abandono ou por revelia pode formular uma requête ao tribunal, pleiteando a rescisão do julgamento (art. 482).

A apelação é o recurso ordinário (art. 491 e ss.), cuja admissão subordinase à autorização da Corte de Apelação (art. 494). A despeito do pedido de autorização dirigido ao tribunal, o apelante deve apresentar as razões do recurso, perante o juízo de primeiro grau, no prazo de 30 dias.

Responde pela sucumbência a parte que for derrotada (art. 477 e ss.).

Embora o CPC não discipline especificamente a coisa julgada, inúmeros dispositivos revelam que o processo civil do Quebec praticamente adota a clássica concepção do instituto, inspirada no princípio da estabilidade dos julgamentos (arts. $165,817.4$, 985). Ademais, a coisa julgada não atinge quem não foi parte no processo. Depois de o julgamento adquirir autoridade de res iudicata, a execução será definitiva.

Excepcionalmente, admite-se, nos arts. 482 a 490, a rescisão do julgado (rétractation de jugement), incluindo-se entre os legitimados o terceiro prejudicado, nas 7 situações catalogadas no art. 483 .

Trata-se, na verdade, de um recurso, a ser interposto no prazo de 15 dias, a contar da data na qual o interessado tomou conhecimento da decisão rescindenda (art. 484). Na hipótese de o legitimado ser menor de idade, tal lapso inicia-se a partir do momento em que atingir a maioridade.

$\mathrm{O}$ art. 540 prevê a hipótese de cumprimento voluntário da decisão condenatória.

$\mathrm{O}$ art. 547 estabelece um rol de hipóteses nas quais a execução provisória é cabível, mesmo na pendência da apelação, dentre elas, $v . g$., nas ações possessórias e nas causas de alimentos.

A execução forçada se inicia com a intimação ao devedor para que ele compareça perante o juiz da causa para ser ouvido sobre o estado de seu patrimônio (art. 543).

A penhora sobre bens do devedor, que deve ser efetivada pelo shérif (a quem também incumbe a alienação destes), está prevista no art. 552, havendo bens impenhoráveis (insaisissables)(art. 553).

A partir do art. 733 e segs., no livro V, o CPC regulamenta os procedimentos especiais. Em primeiro lugar, as medidas provisionais: o sequestro de bens (art. 742 e ss.); e as ordens injuncionais de fazer ou de abstenção (art. 751 e ss.) 
Em seguida, as ações possessórias e petitórias (art. 770 e segs.); as ações em matéria de direito de família, de incapazes e de menores (art. 813 e ss.).

O habeas corpus em matéria civil está regrado nos arts. 851 a 861.

\section{Ações coletivas}

Substituindo a antiga Regra 75 das Supreme Court of Ontario Rules of Practice, novo texto legal regulamentou as ações coletivas na Província de Ontário (Class Proceedings Act, de 1992), que adotou, embora de forma mais detalhada, o mesmo modelo que então vigorava nos Estados Unidos, sob a égide da famosa Regra 23.

Em época atual, a Regra 12 das Ontario Rules of Civil Procedure praticamente ratificou a lei de 1992.

Nota-se que a doutrina especializada tem a exata dimensão da relevância das ações coletivas. Com efeito, segundo assevera Garry Watson - o mais destacado processualista canadense -, os objetivos mais importantes deste mecanismo processual são o de "permitir o maior acesso possível à justiça" e o de "incrementar a eficiência judicial, evitando a desnecessária repetição de demandas análogas". ${ }^{18}$

Para ser tipificada uma ação coletiva, basta que dois ou mais sujeitos de direito estejam representados, seja no pólo ativo, seja no pólo passivo. A adequada representação, como bem esclarece Michael Eizenga, deve recair sobre uma pessoa que atue não apenas em prol do interesse próprio, mas no de toda a classe. E aquela, ademais, deve ter conhecimento pormenorizado dos detalhes atinentes aos elementos de prova para o fim precípuo de melhor subsidiar o advogado da causa. ${ }^{19}$ Ressalte-se, ainda, que, de acordo com o art. 5.e.iii do Class Proceedings Act, o representante (no pólo ativo ou no pólo passivo) deverá apresentar um plano de trabalho a ser desenvolvido durante o procedimento, contendo, inclusive, a forma de comunicação processual aos membros da classe.

A teor do subsequente art. 14.1, o juiz pode admitir, em determinadas circunstâncias, a efetiva participação, no respectivo processo, de um ou mais membros da classe.

Já no que se refere aos limites subjetivos da res iudicata, o julgamento proferido, qualquer que seja o resultado do processo, projeta eficácia aos integrantes

\footnotetext{
18 Class Actions: the Canadian Experience, Duke Journal of Comparative and International Law, 11, 2001, p. 269.

19 A Brief Introduction to Class Proceedings in Ontario, p. 8.
} 
do grupo que não exerceram no prazo determinado pelo juiz, depois de devidamente cientificados do ajuizamento da demanda, o right to opt out (direito de auto-exclusão). ${ }^{20}$

Igualmente moderna e avançada é a sistemática sobre a class action (recours collectif) que vigora na Província do Quebec - a pioneira a adotá-la, em 1978 -, que também seguiu, neste particular, a experiência estadunidense. ${ }^{21}$

Mais recentemente, o instituto veio contemplado nos arts. 999 a 1.051 do Code de Procédure Civile da Província de Quebec.

O art. 999 preceitua que a ação coletiva pode ser promovida por pessoa física, podendo, ainda, ser ajuizada por pessoa jurídica, desde que esta não tenha admitido, como empregados, mais de 50 pessoas nos 12 meses anteriores ao ajuizamento da demanda.

Qualquer integrante da classe poderá ser admitido como interveniente, no intuito de auxiliar o representante adequado na condução do processo (art. 1.017).

A evitar dúvida quanto ao foro competente, a ação coletiva é de competência da Superior Court of Justice (art. 1.000).

A natureza de ação de classe, consoante dispõe o art. 1.002, depende sempre da autorização judicial. De aduzir-se que tal preliminar decisão, admitindo o processamento da ação coletiva, deve, ainda, segundo o art. 1.005: (i) descrever quais os integrantes do grupo serão atingidos por qualquer julgamento; (ii) identificar as principais questões pertinentes ao grupo; e (iii) determinar a notificação dos membros do grupo.

Ademais, neste mesmo ato decisório, o juiz deverá fixar o prazo para ser exercido o direito de auto-exclusão (right to opt out), não podendo ser inferior a 30 dias ou superior a 6 meses, a contar da data da efetiva ciência. Este lapso é "peremptory", a menos que o interessado demonstre a impossibilidade de exercê-lo na fluência do prazo.

No que concerne aos limites subjetivos da coisa julgada, o art. 1.007 bem ressalva que: "Um membro que requereu sua exclusão não é atingido por qualquer julgamento proferido no processo".

Por esta razão, o art. 1.027 dispõe que: "O julgamento final define o grupo e vincula os membros que não se auto-excluíram”. A decisão, pois, deve ter ampla divulgação (art. 1.030).

Afirmam, a propósito, Louise Ducharme e Yves Lauzon que, em matéria de ação coletiva, o tribunal deve desempenhar uma função "agressiva" com o escopo de

\footnotetext{
20 Salvaguardado no art. $9^{\mathbf{o}}$ do Class Proceedings Act. Cf., a respeito, Watson, Borins e Williams, Canadian Civil Procedure, cit., cap. 5, p. 82. Aquele que participa do contraditório como autor goza dos poderes, ônus e faculdades inerentes à sua qualidade de parte (fala-se, inclusive, em dominus litis).

21 V., sobre o tema, Pierre Sylvestre, Le recours collectif: une procédure essentielle dans une société moderne, Service de la formation permanente, v. 115 - Développements récents sur les recours collectifs, p. 39 ss.
} 
preservar as garantias constitucionais em prol dos interesses dos terceiros, vale dizer, dos membros do grupo que não tomaram parte no processo. ${ }^{22}$

Dependendo da natureza da condenação, a execução pode ser coletiva (art.1.031 a 1.036) ou individual (art. 1.037 a 1.044), devendo o interessado, nesta hipótese, requerer a liquidação no prazo de 1 ano (art. 1038), a partir da notificação prevista no art. 1.030 .

8. Meios alternativos de solução dos conflitos

A Regra 75.1, da Província de Ontário, especifica o procedimento da mediação incidental, que pode ser utilizada em apenas algumas regiões.

A requerimento de uma das partes, a mediação é determinada pelo juiz da causa. O mediador pode ser alguém da lista do tribunal ou, mesmo não estando inscrito naquela, ser escolhido pelas partes (R. 75.1.06).

O mediador passa então a estipular um calendário para o desenvolvimento da mediação, que se inicia com uma audiência (mediation session). Em seguida, depois de o mediador elaborar um relatório, passa-se à fase de conciliação. Não sendo possível um acordo, o processo então retoma o seu curso, perante o tribunal (R. 75.1.12).

O Code de Procédure Civile da Província do Quebec, a seu turno, além da já mencionada "tentativa compulsória de conciliação" (item 6, supra), contempla duas espécies de arbitragem.

A primeira delas, regrada nos arts. 383 a 394 (arbitrage par les avocats), é aquela que se instaura, no curso do processo, a requerimento das partes. O árbitro ou árbitros, eleitos pelos litigantes, devem ser advogados ou juízes aposentados.

A arbitragem se desenrola então fora do tribunal, sendo certo que a decisão final dos árbitros deve conter a mesma estrutura da sentença proferida por juiz togado (art. 386). Para ser ela eficaz, depende de homologação judicial (art. 388). Ademais, o art. 393 determina que o laudo arbitral, depois de homologado, desafia o recurso de apelação, "a exemplo de qualquer outro julgamento proveniente da corte de justiça".

A outra espécie de arbitragem, prevista nos arts. 940 a 952, segue o modelo clássico, vale dizer, quando as partes, previamente, instituíram a solução do litígio por meio de árbitros (convention d'arbitrage).

É certo que o procedimento desta também se instaura sob a égide do tribunal togado. Todavia, o art. 940.3, ressalva que o juiz da causa não tem qualquer ingerência na condução da arbitragem. Excepcionalmente, medidas provisionais de urgência podem ser determinadas pelo tribunal (art. 940.5).

22 Le recours collectif québécois, p. 141. 
Cada uma das partes indica um árbitro, sendo que os dois indicados escolhem o terceiro (art. 941).

A decisão proferida pelos árbitros deve ser escrita e fundamentada, admitindo-se julgamento por maioria (art. 945.2).

O julgamento arbitral é eficaz e equiparado à sentença judicial somente após a devida homologação pelo tribunal (arts. 946 e 951.1). O art. 946.4 explicita as hipóteses que obstam o proferimento da decisão homologatória, concernentes a nulidades insanáveis, como, p. ex., a existência de vício no compromisso arbitral celebrado pelas partes.

O único remédio contra a homologação consubstancia-se no pedido de anulação (art. 947), apresentado por uma das partes ao tribunal, no prazo de 3 meses a contar da intimação da decisão.

\section{Advertência final}

Destaque-se, por fim, que a presente exposição tem por finalidade precípua conferir uma visão panorâmica do processo civil que atualmente vigora no Canadá.

Todavia, como foi inicialmente mencionado, a atividade jurisdicional que se desenrola nas cortes canadenses é muito mais complexa, sobretudo no que se refere a inúmeras questões atinentes: a) aos constantes conflitos de lei e de competência entre os tribunais provinciais, e b) aos efeitos das decisões, as quais, por força de convenções internacionais, chegam a projetar direta eficácia até mesmo nos Estados Unidos.

São Paulo, dezembro de 2012.

\section{Referências}

AA. VV. Une nouvelle culture judiciaire, Rapport Comité de révision de la procédure civile, Quebec, 2001.

AUDET, Pierre E. La réforme de la procédure civile de 2002: un jalon de plus vers l'idéal d'un accès à la justice pour tous? 2002 Civil Procedure Reform: Another milestone towards attaining the ideal of access to justice for all? Disponível em: $<$ http://www. cfcj-fcjc.org/docs/2006/audetfr>.

DUCHARME, Louise e Lauzon, Yves. Le recours collectif québécois, Cowansville, Yvon Blais, 1988.

EIZENGA, Michael. A Brief Introduction to Class Proceedings in Ontario, s/ed., 1994.

GARANT, Patrice. Fundamental Rights and Fundamental Justice, The Canadian Charter of Rights and Freedoms, 2. ed., ed. por Gérald-A. Beaudoin e Ed Ratushny, Toronto, Carswell, 1989. 
PERELL, P. The Interlocutory Injunction and Irreparable Harm, Canadian Bar Review, v. 68, 1989.

SYLVESTRE, Pierre. Le recours collectif: une procédure essentielle dans une société moderne, Service de la formation permanente. Développements récents sur les recours collectifs. Cowansville: Yvon Blais, 1999. v. 115.

VEITCH, Edward. Canada, International Civil Procedure. Editado por Christian Campbell. Salzburg: Yorkhill, 2006. v. 1.

VOLTERRA, Sara. La giurisprudenza statunitense nelle pronunce della Corte Suprema Federale del Canada, Scintillae iuris. In: Studi in memoria di Gino Gorla. Milano: Giuffrè, 1994. t. 1.

WAGNER, Charles B. Rules of Civil Procedure in Ontario Changes as a January, 1, 2010.<http:// www.hg.org/article.asp?id=7869>.

WALKER, Janet e Watson, Garry. Preliminary or Summary Proceedings: Scope and Importance - General Report (Common Law). In: XII Congreso Mundial de Derecho Procesal, v. 1, coord. por Marcel Storme e Cipriano Gómez Lara, Universidad Nacional Autónoma de México, México, 2005 .

WATSON, Garry; BORINS, Stephen; WILliAMS, Neil. Canadian Civil Procedure. 2. ed. Toronto: Butterworths, 1977.

WATSON, Garry. A Brief Introduction to Class Proceedings in Ontario. s/ed., 1994. 